\title{
Amostragem por larva-única na vigilância de Aedes aegypti
}

\author{
Single-larva sampling for Aedes aegypti surveillance \\ José Eduardo Bracco, Amaury Lelis Dal Fabbro \\ Superintendência de controlp de Endemias-SUCEN - São Paulo - Brasil (J.E.B.) \\ Secretaria Municipal da Saúde de Ribeirão Proto - Brasil (A.L.D.F.)
}

\begin{abstract}
Com a finalidade de testar a metodologia de amostragem por larva-única na vigilância entomológica do Aedes aegypti, foram pesquisados domicilios do Municipio de Araraquara, SP (Brasil). Nos criadouros que continham larvas de Aedes uma delas foi coletada. Como controle, após a coleta da larva-única, todias as larvas foram coletadas para identlf́lcaçāo posterior. Esse processo foi repetido no laboratório. Dos 447 domicílios visitados, apenas 12 foram considerados positivos e 20 criadouros foram identíficados; destes, 13 continham larvas de Aedes; 5 , larvas de Aedes $\theta$ Culex $\theta 2$, larvas de Cujex. Os resultados mostram o reconhecimento correto, no campo, de todos os criadouros, evidenciando que o método poderia ser utllizado na viglláncia entomológica de municipios sem infestaçāo domiciliar ou infestados apenas com uma única espécie de Aөdes.
\end{abstract}

Aedes. Larva. Controle de mosquitos.

\section{Introdução}

A vigilância entomológica sobre vetores urbanos é aspecto de grande importância no controle de doenças como, por exemplo, dengue e febre amarela.

Quando foi desenvolvida, a metodologia de vigilância sobre larvas de Aedes aegypti preconizava a coleta de todas as larvas de determinado criadouro, o chamado método de "todas as larvas", no qual todas as larvas de um criadouro são coletadas para identificação em laboratório.

Sheppard e col. ${ }^{3}$ (1969), visando à otimizaçăo de recursos, tanto humanos como financeiros, desenvolveram o chamado método de "larvaúnica" que consiste na coleta de apenas uma larva por recipiente positivo.

Com o objetivo de comparar os dois métodos, numa cidade com baixa infestação, foram realizadas pesquisas semanais em domicílios do Município de Araraquara, de março de 1991 à março de 1992, época em que o município encontrava-se pouco infestado pelo Ae. aegypti.

\section{Materlal e Método}

Escolha dos imóveis - Utilizou-se a metodologia usada no sorteio de quadras para coleta de larvas para o cálculo do índice de Breteau (Alves e col. 1,1991 ). Uma vez na quadra sorteada, o técnico numerava as casas no sentido anti-horário, tomando uma esquina como referência, e sorteava duas casas que eram entảo pesquisadas.

Identificação de criadouros - Foi considerado criadouro positivo todo e qualquer objeto que contivesse coleção hídrica com presença de larvas e/ou pupas de culicídeos.

Coleta das larvas - Identificado um criadouro positivo, a conduta do técnico era: primeiro, se ele reconhecesse larvas de Aedes, era coletada uma dessas larvas (amostra A); segundo, eram coletadas todas as larvas do criadouro (amostra B); terceiro, no laboratório, retirava-se outra larva da amostra B, identificada a olho nu como Aedes (amostra C). No caso do técnico não identificar, tanto no campo como no laboratório, larvas de 


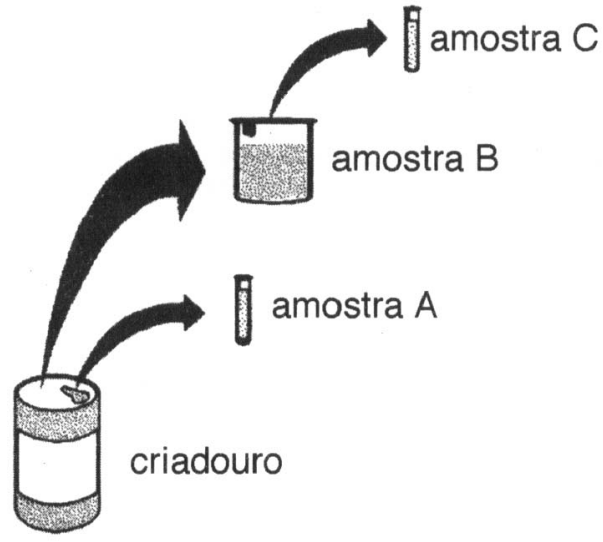

Figura - Tócnica para obtenção das amostras.

Aedes, as amostras A e C não eram coletadas, apenas a amostra $B$ (Figura).

Esses procedimentos visavam detectar diferenças nas situaçôes de campo e de laboratório.

Identificação das larvas - Todas as larvas foram identificadas sob um estério-microscópio marca Olympus, em nível genérico e específico, segundo chave descrita por Forattini ${ }^{2}$ (1965).

\section{Resultados}

Um total de 447 imoveis foram pesquisados entre $26 / 3 / 91$ e $30 / 3 / 92$. Desse total, $12(2,7 \%)$ mostraram-se positivos para larvas de culicídeos.

Nesses imóveis foram encontrados 20 criadouros, dos quais $13(65,0 \%)$ continham apenas larvas de Ae. aegypti e $5(25,0 \%)$ continham formas imaturas de Aedes e Culex. Amostras A e $\mathrm{C}$ foram retiradas desses 18 criadouros, mostrando que o técnico reconheceu-os como positivos para Aedes.

Apenas 2 criadouros $(10,0 \%)$ continham apenas larvas de Culex, e destes nảo foram coletadas as amostras $\mathrm{A}$ e $\mathrm{C}$. No total foram coletadas e identificadas 1.193 larvas, sendo $416(34,9 \%)$ do gênero Aedes (desse total, 401 ou $96,4 \%$ de Aedes aegypti) e $777(65,1 \%)$ do gênero Culex.
As proporçōes de larvas de Aedes, sobre o total de larvas encontradas nos criadouros que continham os dois gêneros em questão, foram de $17,7 \%$; $26,7 \% ; 12,1 \% ; 14,3 \%$ e $5,2 \%$ para cada um dos criadouros encontrados. A média foi de $17,4 \%$.

\section{Discussão}

Apesar do pequeno número de imóveis e recipientes positivos, todos os criadouros que continham larvas do gênero Aedes foram identificados, no sentido de terem sido colhidas as amostras A e C. Tais amostras foram identificadas acertadamente, apesar da pequena proporção de larvas de Aedes nas amostras (variando de um mínimo de $5,2 \%$ até um máximo de $26,7 \%$ ), enquanto que nos criadouros que continham apenas larvas de Culex, as amostras $\mathrm{A}$ e C năo foram coletadas pelo técnico.

Esse nível de acerto foi possível graças a um treinamento simples e rápido, que focaliza as diferenças morfológicas evidentes entre os dois gêneros, basicamente o comprimento do sifāo e o tamanho da cabeça em relação ao tórax (Forattini $\left.{ }^{2}, 1965\right)$. Acredita-se que a experiência do trabalho cotidiano no campo capacita os funcionátios que atuam nessa área e com um simples treinamento, podem distinguir, ainda no campo, larvas de Aedes das de Culex, o que poderia significar economia de tempo e recursos para o sistema de vigilância.

Devido ao pequeno número de recipientes positivos, outros estudos devem ser feitos e se pode contar com uma amostra estatisticamente representativa.

\section{Agradecimentos}

À Dra. Denise Schout e ao Prof. Dr. Fernando A.O.M. de Azevedo Corrêa, ambos da SUCEN, pelas valiosas sugestōes. Aos Srs. Joåo Maurício da Silva Filho e José Wilson Torres pela colaboraçāo nas atividades de campo e de laboratório. 


\section{Referências Blbliográticas}

1. ALVES, M.C.G.P.; GURGEL, S.M.; ALMEIDA, M.C.R.R. Plano amostral para o cálculo de densidade larvária de Aedes aegypti e Ae. albopictus no Estado de Săo Paulo, Brasil. Rev.Saúde Pública, 25:251-6, 1991.
2. FORATTINI, O.P. Entomologia médica. São Paulo, EDUSP, 1965. v.2.

3. SHEPPARD, P.M.; MACDONALD, W.W.; TONN, R.J. A new method of measuring the relative prevalence of Aedes aegypti. Bull.World Health Organ., 40:467-8, 1969.

\begin{abstract}
Buildings in Araraquara city, Southeastern Brazil, were searched during a year for the presence of Aedes larvae using singie larva sampling in order to check the single-larva methodology. in those breeding places in wich Aedes larvae were found, one of them was collected. As a control, after the single larva had been collected, all the larvae from the breeding place were collected for later identification. This process was repeated in the laboratory. Of the 447 domiciles searched, 12 were considered positive and 20 breeding places were found. Of the breeding places, 13 contained Aedes larvae, 5 both Aedes and Culex larvae and 2 Culex larvae only. The results show that all the breeding places in the fleld were properly recognited showing the method may be used for Aedes surveillance in cities infested with one species only or without any domiciliary infestation.
\end{abstract}

Aedes. Larva. Mosquito control. 